\title{
Sociedade Brasileira de Educação Matemática, 30 anos: sujeitos, políticas e produção de conhecimento
}

\section{Brazilian Society of Mathematics Education, 30 years: subjects, policies and knowledge production}

\author{
Filipe Santos Fernandes* \\ ORCID iD 0000-0002-2964-3582 \\ Wagner Rodrigues Valente ${ }^{* *}$ \\ ORCID iD 0000-0002-2477-6677
}

\begin{abstract}
Resumo
A Sociedade Brasileira de Educação Matemática (SBEM) comemorou, em 2018, seus 30 anos de fundação. Visando celebrar a data, o VII Seminário Internacional de Pesquisa em Educação Matemática (SIPEM), realizado em novembro de 2018, em Foz do Iguaçu (Paraná, Brasil), organizou, como uma de suas atividades, uma mesa redonda que tinha como tema: A SBEM e a pesquisa em Educação Matemática no Brasil. O interesse pelo registro dessa atividade, fundamentado no reconhecimento da importância da SBEM para a Educação Matemática brasileira, é a principal motivação para a composição deste texto. Nele realizamos uma discussão sobre o envolvimento de nossa Sociedade com a construção de uma comunidade científica em Educação Matemática e problematizamos, com base em uma das falas proferidas no evento, as relações da SBEM com o ensino de Matemática e com a formação de professores que ensinam Matemática a partir de movimentos histórico-políticos que marcam a trajetória da Sociedade, particularmente o engajamento de seus sujeitos com responsabilidades coletivas em diferentes tempos, inclusive os porvir. Esperamos que as compreensões elaboradas neste e nos outros textos que compuseram a mesa, que serão publicados em outras edições do BOLEMA, contribuam para compartilhar e avaliar nossa atuação como Sociedade, compondo e pensando nossa memória coletiva e nosso acúmulo histórico para o enfrentamento dos desafios de nosso tempo.
\end{abstract}

Palavras-chave: Disciplinarização. Educação Matemática. Educador Matemático. História da Educação Matemática. Responsabilidade.

\begin{abstract}
The Brazilian Society of Mathematical Education (SBEM) celebrated the 30th anniversary of its founding in 2018. In order to celebrate the date, the VII International Seminar on Research in Mathematical Education (SIPEM), held in November 2018 in Foz do Iguaçu (Paraná, Brazil), organized as one of its activities a roundtable discussion

\footnotetext{
* Doutor em Educação Matemática pela Universidade Estadual Paulista "Júlio de Mesquita Filho" (UNESP/Rio Claro). Professor da Faculdade de Educação da Universidade Federal de Minas Gerais (UFMG), Belo Horizonte, Minas Gerais, Brasil. Membro do Grupo de Pesquisa História Oral e Educação Matemática (GHOEM) e do Núcleo de Estudos e Pesquisas em Educação do Campo (NEPCampo). Endereço para correspondência: Avenida Presidente Antonio Carlos, 6627, Pampulha, Belo Horizonte, Minas Gerais, Brasil, CEP: 31270-901. E-mail: fernandes.fjf@gmail.com.

** Livre Docente em Educação pela Universidade Federal de São Paulo (UNIFESP). Professor do Departamento de Educação - Curso de Pedagogia - da Universidade Federal de São Paulo (UNIFESP), Guarulhos, São Paulo, Brasil. Coordenador do Grupo de Pesquisa de História da Educação Matemática (GHEMAT). Endereço para correspondência: Estrada do Caminho Velho, 333, Jd. Nova Cidade, Guarulhos, São Paulo, Brasil, CEP: 07252312. E-mail: ghemat.contato@gmail.com.
} 
that had as its theme: SBEM and the research in Mathematics Education in Brazil. The interest in recording that activity, based on the recognition of the importance of SBEM for Brazilian Mathematical Education, is the main motivation for the writing of this text. In this article, we develop a discussion about our society's involvement with the construction of a scientific community in Mathematics Education. Based on one of the speeches given at the event, we aim to discuss the SBEM's relationships with teaching mathematics and with the formation of mathematics teachers from historical-political movements that mark the trajectory of the society, particularly the engagement of its subjects with collective responsibilities at different times, including the times yet to come. We hope that the understandings elaborated in this and other texts presented in this round-table discussion, which will be published in other editions of BOLEMA, contribute to share and evaluate our actions as a Society, constituting and thinking our collective memory and our historical accumulation to face the challenges of our time.

Keywords: Disciplinization. Mathematical Education. Mathematical Educator. History of Mathematics Education. Responsibility.

\section{Introdução}

A Sociedade Brasileira de Educação Matemática (SBEM) completou, em 2018, seus 30 anos de fundação. Para celebrar a data, o VII Seminário Internacional de Pesquisa em Educação Matemática (SIPEM), realizado em novembro de 2018, promoveu como uma de suas atividades uma mesa redonda com o título A pesquisa em Educação Matemática nos 30 anos da SBEM, ficando o Grupo de Trabalho 15 - História da Educação Matemática, por solicitação da Diretoria Nacional Executiva, responsável por sua idealização, proposição e realização.

Após discussões dos membros do Grupo, ficou decidida que a mesa teria como intencionalidade a promoção de um balanço crítico da atuação da SBEM, em um viés historiográfico, com atenção a sua participação nas políticas públicas educacionais, na produção de conhecimento, na formação de professores e no ensino de Matemática. Foram convidados para participar da atividade, sob coordenação do professor Wagner Rodrigues Valente (UNIFESP), o professor Filipe Santos Fernandes (UFMG), a professora Elisabete Zardo Búrigo (UFRGS) e a professora Neuza Bertoni Pinto (REAMEC).

O interesse pelo registro dessa atividade, fundamentado no reconhecimento da importância da SBEM para a Educação Matemática brasileira, é a motivação para a composição deste texto. Nele apresentamos uma discussão sobre o envolvimento da SBEM com a constituição de uma comunidade científica em Educação Matemática no Brasil, desenvolvida pelo professor Wagner Rodrigues Valente, e uma das falas que compôs a mesa, proferida pelo professor Filipe Santos Fernandes, que teve como objetivo problematizar as relações da SBEM com o ensino de Matemática e com a formação de professores que ensinam Matemática a partir de movimentos histórico-políticos que marcam a fundação e consolidação da Sociedade. As demais exposições da mesa redonda - das professoras Elisabete Zardo Búrigo e Neuza Bertoni Pinto - serão apresentadas em outras edições do BOLEMA. 
Esperamos que as compreensões elaboradas neste e nos outros textos contribuam para compartilhar e avaliar nossa atuação como Sociedade, compondo e repensando nossa memória coletiva e nosso acúmulo histórico para o enfrentamento dos desafios de nosso tempo.

\section{A SBEM e a pesquisa em Educação Matemática no Brasil}

A afirmação de um campo científico, um campo disciplinar, poderá ocorrer, pelo menos, de dois modos. Um primeiro, a partir da existência de práticas profissionais existentes e que desejam, por meio de seus praticantes, constituir saberes da profissão de maneira a poder formar, por processos de escolarização, os seus futuros oficiais. Haverá que existir um corpo de saberes formalizados, sistematizados para ser transmitido, apropriado e que chancele a condição profissional de quem o possui. Aqui, de forma um tanto simplista, poderíamos dizer que ocorre um movimento da prática para a teoria; de uma prática empírica existente para uma sistematização dos processos e dinâmicas nela envolvidos. Trata-se do desenvolvimento de um campo disciplinar a partir de um campo profissional já existente. Exemplos disso são as ciências médicas, as ciências políticas etc.

Um segundo modo de assentamento de um campo disciplinar refere-se ao movimento oposto: da teoria para a prática. Saberes sistematizados ensejam a possibilidade de serem transformados em guias de novas práticas profissionais a partir, muitas vezes, do intenso diálogo com outros campos disciplinares já constituídos. Dizendo de outro modo, um campo disciplinar já existente pode dar origem a diferentes profissões. Podemos citar, aqui, o psicólogo, o orientador profissional, o psicopedagogo etc.

Em resumo, há processos de disciplinarização secundária - da prática para a teoria - e de profissionalização secundária - da teoria para a prática (HOFSTETTER; SCHNEUWLY, 2017).

A Educação Matemática, nesse enquadramento, insere-se no primeiro caso. Há práticas já existentes. Há práticas didático-pedagógicas. Práticas do professor que ensina Matemática desde há muito. O processo de disciplinarização secundária, com vistas à consolidação da Educação Matemática, mostra embates e dificuldades com relação à sistematização do saber vindo dessas práticas docentes. Historicamente, construiu-se uma relação ambígua relativamente ao saber definidor da profissão: a Matemática. Esse campo disciplinar - a Matemática - tem sido considerado como o próprio saber profissional do professor que ensina Matemática. Tem razão o senso comum, até os dias atuais, confundirem o professor de Matemática com o matemático... 
Numa passada d'olhos pela história da Educação Matemática, tem-se os militares, particularmente os engenheiros militares, no uso das matemáticas para as suas lides bélicas como uma referência primeira do professor que ensina Matemática. O engenheiro, o militar e o matemático confundiam-se: profissionais que colocavam em uso prático os preceitos matemáticos. Os manuais e tratados militares expressavam o saber dessa profissão. Eram verdadeiros guias de aplicação matemática para a guerra e para a defesa de reinos, vilas e praças (VALENTE, 2007).

Num corte brusco no tempo, podemos evocar a criação das Faculdades de Filosofia. Nelas foram organizadas e sistematizadas as rubricas matemáticas para formar os matemáticos de profissão. Expurgada de suas ligações à prática militar, a Matemática organiza-se em disciplinas, compondo um campo disciplinar próprio. A docência nada mais seria do que um complemento dessa formação. E ela esteve e ainda está organizada a partir da própria Matemática, da sua estruturação, do seu encadeamento lógico-dedutivo. Ser professor seria saber como se encadeiam os conteúdos matemáticos. E eles estão organizados na marcha que vai do simples ao complexo. Ser professor seria conhecer essa trajetória para a prática de sua exposição. Uma única matemática que se difere daquelas praticas na escola apenas no nível em que será apresentada aos alunos e estudantes. Irá dos primeiros elementos até aqueles mais complexos. Para citar uma voz discordante, poderemos ouvir o que diz Maria Montessori a respeito dessa perspectiva de ensino matemático:

\begin{abstract}
os mestres começarão o ensino pelas linhas, pelos ângulos ou com os números, e o primeiro problema será, antes de tudo, de saber o que é o mais simples; a partir disso, o ensino deverá começar. Eu me lembro de discussões de eminentes professores num congresso de matemática, em que se perguntavam se era mais simples contar os números numa sucessão natural (números cardinais) ou considerá-los segundo a ordem e o lugar que eles ocupam reciprocamente (número ordinais). O problema relativo à ordem dos saberes sucessivos estando resolvido, procedia-se ao ensino; fazer compreender primeiramente, a coisa mais simples e encadear, consequentemente, o precedente com o seguinte, por ordem de dificuldade (complexidade), passando do desconhecido ao conhecido (MONTESSORI, 1934 [2007], p. 14).
\end{abstract}

A formação de professores em nível superior no Brasil tem por referência inicial a criação da Faculdade de Filosofia, Letras e Ciências Humanas da Universidade de São Paulo, em 1934. O modelo adotado para formar professores ficou conhecido na história como "3+1". Na realidade, a criação dessa Faculdade não tinha intenção inicial de formar professores. A ideia era formar pesquisadores. Professores que se ocupassem do Ensino Superior e da pesquisa. A licenciatura não tinha o status do bacharelado. Em termos de nomenclatura, era uma "licenciatura cultural", sem o caráter profissional da docência que poderia ser adquirida com a complementação de matérias pedagógicas (CASTRO, 1974). 
De todo modo, o modelo consolidou-se: três anos para os campos disciplinares e um ano para as matérias pedagógicas. Assim, depois de aprender os conteúdos de uma dada área disciplinar (Matemática, História Natural, Letras, Ciências Sociais, Química etc.) haveria disciplinas pedagógicas direcionadas a formar o professor (Didática Geral e Especial, Psicologia Educacional, Administração Escolar etc.).

Esse modelo de formação de professores espalhou-se por todo o Brasil e, ainda hoje, mostra-se orientador, na prática, de grande parte dos cursos de graduação, mesmo que em termos teóricos os cursos sejam pensados de modo articulado, seguindo as resoluções oficiais. Primeiro aprende-se o conteúdo; depois, como ensinar esse conteúdo. Não raro, os estudantes das áreas disciplinares emitem juízos sobre as experiências vividas no "1" do " $3+1$ ": trata-se de uma perda de tempo... Salvo raras exceções, as disciplinas pedagógicas pouco seduzem os futuros professores.

E como o professorado das diferentes disciplinas e campos disciplinares aprendem a profissão de professor? Resposta pronta, vinda de muitos estudos: dando aulas, mirando-se nos professores que têm na graduação etc. O campo científico das Ciências da Educação pouco parece contribuir para a formação dos licenciandos, salvo os licenciandos de Pedagogia. Neste último caso, ocorre uma inversão: ao invés de privilegiar conteúdos de ensino, vindos das áreas disciplinares, são privilegiados os processos, os métodos, o conhecimento do aluno e seu modo de aprender etc. Mas, mesmo nesse contexto, recaem sobre esses cursos declarações sobre o excesso de discussões dos chamados "Fundamentos da Educação", como a Filosofia da Educação, a Psicologia da Educação, a História da Educação, as discussões teórico-curriculares, entre outras, pouco articuladas com a dimensão profissional.

É fato a existência crônica de uma ruptura entre os campos das Ciências da Educação e aquele das Disciplinas Científicas. O primeiro relativo aos saberes pedagógicos; o segundo, originário de formas didáticas construídas a partir dos próprios conteúdos a ensinar.

Quando um professor de Matemática do Ensino Médio ensina, por exemplo, Trigonometria, dificilmente ele utiliza processos pedagógicos que levem em conta o nível de maturidade de seus alunos ou teorias de aprendizagem que impliquem modos de docência diferenciados face ao público escolar. Ele segue, em geral, a lógica dos conteúdos de ensino, da sequência já perpetuada dos elementos que devem ser ensinados antes, durante e depois. E tal sequência vem oficializada nos programas, nos livros didáticos, nas apostilas, nas vivências pessoais como aluno de Trigonometria etc. E as inovações que o professor traz para suas aulas não são fruto de saberes sistematizados e acumulados por meio das teorias pedagógicas. Vêm 
das experiências de ensino e de aprendizagem do professor e do modo como ele reelaborou tais experiências, buscando sucesso em sua prática docente.

Quando um professor do Ensino Fundamental I se vê diante do ensino de Geometria para crianças, não raro, mostra-se reticente. Trata o tema mais para o aspecto do desenho, do desenho livre das crianças, do que tendo em conta os objetos matemáticos geométricos que são importantes no ensino, de modo a que a criança possa caminhar em direção à aprendizagem de que "bola não é circunferência". Há uma tendência de desvalorização dos conteúdos em favor das produções das crianças, sejam elas quais forem, mesmo distantes do caminho da posse dos conteúdos abstratos da Geometria.

Como já disse um grande mestre - que à memória foge o nome, ficando somente o dito: “às vezes é preciso caricaturar para caracterizar”. Esses exemplos, ainda que caricatos, podem caracterizar os resultados advindos da ruptura que ocorre entre as Ciências da Educação e as Disciplinas Científicas.

A Educação Matemática como campo de pesquisa, organizada a partir da docência em Matemática e do questionamento do saber profissional do professor que ensina Matemática e de suas implicações para a construção de uma sociedade direcionada a ideais democráticos, parece colocar no centro dos debates o saber de formação profissional do professor, do professor que ensina Matemática, cunhando a figura do "educador matemático". Terá esse novo profissional a sua formação vinda de saberes organizados e sistematizados pela pesquisa resultante da confluência de diferentes campos das Ciências da Educação e do próprio campo disciplinar da Matemática. E será interessante estudar esse movimento de produção e sistematização de saberes; os processos e dinâmicas que sistematizam o saber próprio do educador matemático, conjugando experiências docentes e saberes acumulados que ganham fóruns de discussão e buscam organizarem-se em modos igualmente disciplinares.

A SBEM, na sua dimensão de Sociedade que congrega, em si, uma comunidade científica, vem tendo papel fundamental para a sedimentação de consensos sobre a formação de professores de Matemática. Que saberes deverão participar da formação daqueles que ensinam Matemática? Em meio às variadas tendências já assentadas da Educação Matemática, o debate dos resultados de pesquisas sobre esse elemento fundamental de caracterização profissional vem ganhando prioridade. Que Cálculo deve estar presente na formação do licenciado? Que papel deverá ter a História da Educação Matemática nas práticas do futuro professor? Que significado terão as Tecnologias da Informação e Comunicação para a atuação do docente em Matemática? Como a resolução de problemas em termos de um método poderá reorganizar a formação do professor? Tais perguntas, para citar algumas delas, vindas das 
diferentes vertentes da Educação Matemática, parecem apontar para um mesmo foco: a organização de uma nova Matemática para a formação dos licenciandos.

E essa forma de indagação com e sobre o saber matemático na formação de professores que ensinam Matemática intenta romper com o paradigma do " $3+1$ ”. Não trata a Matemática como um invariante a necessitar de didáticas especiais... Essa nova forma de indagação vem sendo gestada no âmbito das práticas de nossa Sociedade, a dos educadores matemáticos, que têm sido formados há pelo menos trinta anos. Processos e dinâmicas de sistematização de saberes envolvem décadas de elaboração; experiências exitosas de práticas docentes não são institucionalizadas da noite para o dia. Mas atestar a existência desse movimento é algo animador. E esse movimento tem sido impulsionado pela SBEM e, particularmente, pelas diferentes ações que a Sociedade tem organizado.

\section{A SBEM e seus sujeitos: afinal, quem somos nós?}

O estudo das instituições que firmam a Educação Matemática nos cenários político, científico e acadêmico, como é o caso da SBEM, permite compreender processos que participam intensamente da formação de professores e pesquisadores brasileiros desde os primeiros movimentos de idealização da Sociedade na VI Conferência Interamericana de Educação Matemática (CIAEM), em Guadalajara (México), passando pela fundação oficial da Sociedade Brasileira de Educação Matemática, no II Encontro Nacional de Educação Matemática, em Maringá (PR), até os dias atuais. Na maturidade que lhe cabe, podemos dizer, sem dúvidas, que a SBEM figura como instituição consolidada que representa os diversos sujeitos individuais e coletivos que compõem a Educação Matemática brasileira. Após 30 anos de atuação, uma memória coletiva da SBEM anima e fortalece grupos de jovens professores e pesquisadores que veem nessa Sociedade um abrigo, um caminho, um coletivo, uma luta e uma oportunidade de estar com os outros e seguir.

Na comemoração ${ }^{1}$ realizada VII Seminário Internacional de Pesquisa em Educação Matemática, somos convidados a pensar as relações da SBEM com o ensino de Matemática e com a formação de professores que ensinam Matemática. Um tema amplo, de muitas entradas. Poderíamos, por exemplo, seguir pela história política e dizer das ações da Sociedade na

\footnotetext{
${ }^{1} \mathrm{O}$ sentido de comemorar compartilha, neste texto, o desenvolvido por Gomes (2016, p. 430): "É oportuno sublinhar que qualquer comemoração não é apenas uma rememoração de um evento do passado, digno de memória. A comemoração é um processo ativo e dirigido da memória coletiva, sempre a partir do presente, e o presente é o 'lugar da construção de um certo tipo de visibilidade do passado, que ilumina alguns sentidos, congela outros, ou até mesmo recusa alguns' (CARDOSO, 1998, p. 2)”.
} 
constituição e na articulação de programas de ensino e de formação, muitas vezes articuladas a ações governamentais; poderíamos também seguir pela história cultural e tratar do estabelecimento das representações da SBEM em um dado período e lugar; poderíamos, ainda, seguir pela história do pensamento e dizer dos efeitos da fundação e atuação da Sociedade na produção de conhecimentos sobre o ensino de Matemática ou sobre a formação de professores. Parafraseando a pesquisadora Suely Rolnik: as entradas são algumas; as saídas, múltiplas.

Contudo, ainda que valorizemos todas essas possíveis entradas no tema, nossa opção é tratar de uma história da SBEM na sua relação com processos de ensino e formativos abordando, fundamentalmente, uma de suas dimensões. Essa dimensão passa pela reinclusão dos sujeitos, das subjetividades e dos processos de subjetivação naquilo que chamamos de "história". Marc Bloch, célebre historiador francês, afirma que "o objeto da história é, por natureza, o homem. Digamos melhor: os homens. Mais que o singular, favorável à abstração, o plural, que é o modo gramatical da relatividade, convém uma ciência da diversidade" (BLOCH, 2001, p. 54). São, portanto, o olhar para o diverso e a possibilidade de relativizar e conjugar os tempos e espaços das vidas humanas duas das principais tarefas daquele que se dedica a compreender e escrever uma história. Nesse sentido, para entender a história da SBEM, parecenos razoável tratar de nós mesmos, membros dessa Sociedade. Quem somos nós, membros da SBEM $?^{2}$

Nesses 30 anos de atuação, os laços da SBEM com questões relacionadas com o ensino de Matemática e com a formação de professores são inevitáveis. Somos, dizendo a grosso modo, um coletivo dedicado a propor e avaliar questões de caráter educacional, científico, social e cultural sobre a Educação Matemática e, dado o perfil dos associados de nossa Sociedade, uma maioria composta por professores de Matemática ou formadores de professores de Matemática, somos inevitavelmente alcançados por questões que nos tocam pelo viés do ensino ou da formação. Entretanto, a pergunta “quem somos nós?” não interroga quem são os associados da SBEM, os sujeitos individuais ou coletivos que compõem nossa Sociedade. Em um contexto de uma história institucional, perguntar "quem somos nós?" significa compreender que sujeitos são esses que emergem com a fundação e com a atuação da SBEM, que discursos proferem, que lutas reivindicam, que espaços ocupam e pretendem ocupar, que

\footnotetext{
${ }^{2}$ Esta questão surge da temática do projeto A posição científico-acadêmica da Educação Matemática no Brasil: representações, instituições e políticas, coordenado por um dos autores deste texto, Filipe Santos Fernandes, e financiado pelo Conselho Nacional de Desenvolvimento Científico e Tecnológico (CNPq). O objetivo do projeto é elaborar compreensões de como se dá a emergência do educador matemático no Brasil, posição subjetiva dedicada e autorizada a compreender e a orientar relações entre a educação, o ensino e a Matemática. Nesse projeto, o papel de instituições como a SBEM é marcadamente importante e, por esse motivo, a questão colocada neste texto está imersa em suas discussões.
} 
posições assumem e quais solicitam. Perguntar “quem somos nós?” seria, portanto, ponderar o papel que a instituição SBEM desempenha na produção de nós mesmos ou, dizendo de outro modo, perguntar sobre como o pertencimento a essa Sociedade nos impõe compromissos e responsabilidades.

É partindo desse sentido que apresentamos a intenção central deste texto: pretendemos tratar de uma relação da SBEM com processos educacionais e formativos delineando possíveis reponsabilidades que somos convidados a assumir como sujeitos dessa Sociedade, sugerindo ações responsivas frente ao nosso acúmulo histórico e às demandas de nosso tempo.

A primeira responsabilidade que trataremos pode ser indicada em termos de responsabilidade epistemológica. Seja nas orientações ligadas ao ensino de Matemática ou à formação de professores, assumirmos nossa responsabilidade epistemológica significa reivindicarmos espaços e reconhecimento como sujeitos qualificados para a proposição, gestão e atuação nas políticas educacionais voltadas à habilitação daqueles que ensinam Matemática. Somos, ainda que em divergências teórico-epistemológicas, as posições subjetivas que se dedicam a produzir conhecimentos que estabelecem relações entre o ensino, a educação e a Matemática, sendo nosso papel exigir a autorização e a legitimidade de nossas falas e orientações sem descuidar da diversidade que sempre sustentou e enriqueceu o que fazemos.

Como sabemos, os movimentos de fundação da SBEM, há 30 anos, são acompanhados de processos de ocupação de postos nas instituições de Ensino Superior por profissionais que se dedicavam a produzir reflexões e pesquisas com foco nas múltiplas relações entre o ensino, a aprendizagem, o contexto histórico, social e cultural e o conhecimento matemático. Nesses anos de atuação, fica evidente o engajamento da Sociedade na construção de uma comunidade científica e educacional que, congregando professores da Educação Básica e do Ensino Superior, pesquisadores e gestores, lutasse para garantir, de um lado, o financiamento, a produção e a circulação dessas reflexões e pesquisas e, de outro, sua inserção, diálogo, avaliação e impacto junto às políticas educacionais. Nossa Sociedade nasce, então, em um cenário de reivindicação de um lugar de fala sobre o ensino de Matemática e sobre a formação de professores de Matemática; um lugar que assume seu contorno político mais intenso nos cursos voltados à habilitação daqueles que ensinam ou ensinarão Matemática em nosso país.

Hoje, esse lugar é ocupado prioritariamente por matemáticos, mas isso nem sempre foi assim. Se dermos um passo mais largo no passado, observando períodos anteriores aos 30 anos que comemoramos, vemos nas propostas de formação de professores de Matemática das Faculdades de Filosofia, Ciências e Letras elementos que nos ajudam a entender como se deu a ocupação desse lugar institucional. Naquele tempo, a primeira metade do século XX, os 
modos de ensinar e aprender Matemática eram ditados quase que exclusivamente por engenheiros, profissionais que, no autodidatismo e no improviso, em um compromisso que não era estranho ou alheio à conjuntura social da época, assumiam o lugar de fala sobre a Matemática e seu ensino. A criação das Faculdades de Filosofia marcou, então, um repensar desse lugar: os egressos dessas Faculdades, os "matemáticos profissionais", tornar-se-iam não só os sujeitos legítimos para o desenvolvimento de um conhecimento matemático de natureza teórico-científica, mas também os mais bem qualificados para ditar os rumos da docência no ensino secundário e no curso normal ${ }^{3}$.

Contudo, ao passo que as Faculdades de Filosofia inauguraram no Brasil um processo de ruptura profissional, colocando as realizações luminosas dos matemáticos no centro do debate sobre o ensino de Matemática e a formação de professores, algo singular e absurdamente novo àquele tempo, vemos as mesmas Faculdades de Filosofia exigirem, como que em uma sombra dessas iluminações, profissionais que tensionassem as relações entre o ensino, a educação e a Matemática visando à formação de professores. Esses tensionamentos, como bem tem mostrado os estudos em História da Educação Matemática ${ }^{4}$, impõem a emergência de

\footnotetext{
${ }^{3}$ Há um conjunto de trabalhos que se debruçam sobre questões da formação de professores de Matemática nas Faculdades de Filosofia, Ciências e Letras no Brasil, sendo citados apenas dois aqui. O primeiro, de André Luis Mattedi Dias e intitulado Da bossa das matemáticas à educação matemática: defendendo uma jurisdição profissional, expressa uma preocupação pelo modo como determinadas profissões se institucionalizam historicamente, descrevendo processos pelos quais acontece uma "redefinição e reorganização do ensino da matemática, com o surgimento de novas instituições profissionais específicas, de uma associação de professores licenciados, de uma faculdade para formação especializada de professores, com a realização de uma série de eventos profissionais, que mobilizaram especialistas em debates, que resultaram em pesquisas, em publicações, em intercâmbio, em suma, que resultaram nas tentativas de valorização e reconhecimento de um novo tipo de profissional do ensino, que dominava novos conhecimentos matemáticos e pedagógicos, que proclamava novos valores éticos, que seguia novos métodos etc" (DIAS, 2002, p. 8-9). O segundo, o projeto de pesquisa coordenado por Filipe Santos Fernandes, A posição científico-acadêmica da Educação Matemática no Brasil: representações, instituições e políticas, já mencionado neste texto, investigou, em uma de suas frentes, como a formação de professores de Matemática da Faculdade de Filosofia de Minas Gerais, em Belo Horizonte no início do século XX, “promoveu a necessidade de profissionais qualificados a 'ensinar a ensinar', exigindo não só um novo saber no espaço científico-acadêmico, mas também a constituição de uma posição subjetiva no ensino superior que, em uma perspectiva profissional, estaria autorizada a 'ensinar a ensinar matemática' [...], profissionais dedicados a pensar, a discutir e a produzir conhecimento em torno das relações entre o ensino, a educação e a matemática visando à formação de professores de matemática para o Ensino Secundário e para o Curso Normal" (FERNANDES; ARAÚJO; COSENZA, 2019, p. 12). Esses trabalhos evidenciam preocupações do campo da História da Educação Matemática com movimentos profissionais que, de algum modo, indicam caminhos para a compreensão da emergência e da consolidação da Educação Matemática no espaço científico-acadêmico brasileiro.

${ }^{4}$ Destacaremos, aqui, dois projetos desenvolvidos por grupos de pesquisa em História da Educação Matemática que têm contribuído com essas reflexões. O projeto Mapeamento da Formação e Atuação de Professores que ensinam/ensinaram Matemática no Brasil, desenvolvido pelo Grupo de Pesquisa História Oral e Educação Matemática (GHOEM), tem mostrado como dinâmicas e tensões institucionais, políticas, territoriais e sociais vinculadas à formação de professores de Matemática no Brasil promovem, em distintos tempos e espaços, a constituição de diferentes ideários, modelos e procedimentos de formação de professores de Matemática, notoriamente marcados pelos signos da carência e da urgência. Outro projeto, em desenvolvido pelo Grupo de Pesquisa de História da Educação Matemática no Brasil (GHEMAT) e intitulado A matemática na formação de professores e no ensino: processos e dinâmicas de produção de um saber profissional, 1890-1990, tem como foco
} 
posições subjetivas que, pelas vias da construção de novos saberes, articulados às dinâmicas de poder dos espaços institucionais que atuavam, passam a reivindicar esse lugar sob a égide de disciplinas como a Didática Especial, a Prática de Ensino ou o Estágio Supervisionado. Talvez, o início do século XX marque a intensificação de forças que, apenas na segunda metade do século, evidenciariam um novo cenário de ruptura profissional, com a existência de novos sujeitos que, intitulados "educadores matemáticos", reivindicariam o lugar de fala sobre o ensino de Matemática e sobre a formação de professores para a Educação Básica.

Pensar essa disputa profissional do início do século XX, ainda que aparentemente distante da fundação e atuação da SBEM nesses 30 anos, nos anima e nos ajuda a compreender a responsabilidade epistemológica que podemos assumir como Sociedade. Por um lado, poderíamos assumir um projeto de profissionalização da Educação Matemática que, tomando por base dimensões epistemológicas, reivindicaria uma luta pelo controle de um corpo de conhecimentos sobre o ensino de Matemática e suas implicações, criando disputas com outros grupos, como o grupo dos matemáticos, na busca por modelos, padrões e valores visando obter reconhecimento profissional e político.

Entretanto, de outro modo, e talvez de um modo mais interessante, poderíamos permanecer nas sombras das iluminações de nosso tempo, garantindo-nos as atitudes de suspeição e resistência a tantos discursos que procuram impor, padronizar ou valorar a Matemática e sua presença na cultura escolar. Poderíamos, como responsabilidade, mobilizar nossa Sociedade não para delimitarmos nossas fronteiras epistemológicas e consolidarmos nossa posição profissional por meio da demarcação de objetos de investigação, mas para delinearmos nossos interesses ético-políticos e colocarmos nossa posição profissional e nossos objetos de investigação a seu serviço, em um viés radicalmente democrático e, para usar o termo das pesquisadoras Celi Espasandin Lopes e Beatriz D’Ambrosio, insubordinado.

Em sua fala no XII Encontro Nacional de Educação Matemática, realizado em 2016, e, posteriormente, em publicação na revista Perspectivas da Educação Matemática, o professor Antonio Miguel nos convida a

trazer ao debate uma agenda política de resistência e luta que possa colocar a educação matemática escolar, a pesquisa acadêmica em educação matemática e a formação de professores para a educação básica em sintonia com um projeto de democratização política, social, cultural e econômica de todas as nossas instituições, particularmente, a instituição escolar (MIGUEL, 2016, p. 326).

os saberes objetivados elaborados em processos históricos e dinâmicas articuladas entre a formação de professores e o ensino de Matemática, investigando um conjunto de ideias, saberes, circunstâncias e sujeitos que se direcionam à tarefa de 'ensinar a ensinar matemática', particularmente nas condições históricas da formação de professores e do ensino de Matemática do final do século XIX e século XX. Evidentemente, outros grupos de pesquisa e projetos podem atuar em linhas semelhantes, sendo este destaque fruto apenas do envolvimento pessoal dos autores com os grupos citados. 
Esse convite de Antonio Miguel, se visto ao lado da pergunta “quem somos nós?”, pode ser entendido como o desenho de uma segunda responsabilidade, que apresentaremos como responsabilidade política.

Em sua tese de doutorado, Denizalde Pereira (PEREIRA, 2005) chama a atenção para o movimento democrático que alicerçou a fundação da SBEM; um movimento marcado pela reivindicação da convivência em Sociedade de posições distintas, mas afinadas na intenção da construção de nossa Sociedade. Denizalde evidencia uma SBEM que não apenas nasce da democracia, de um processo democrático articulado entre seus membros e evidenciado, por exemplo, na primeira formulação de nosso estatuto, mas de uma SBEM que nasce para a democracia.

Por isso, falar de nossa responsabilidade política como sujeitos da SBEM não é apenas tratar do compromisso com as formas de gestão democrática de nossa Sociedade, mas de nosso radical comprometimento com a construção e com a manutenção da democracia em nosso país. A história da SBEM não só dialoga com um sentido prescritivo de democracia, como valor inerente que define as formas de ação e de trabalho qualificadas com um determinado conceito - uma sociedade democrática, uma matemática democrática, uma educação democrática -, mas com um sentido descritivo que reivindica a participação da SBEM na afirmação da democracia como forma e regime de governo.

Seguindo essa ideia, devemos vivificar uma história da SBEM que se confunde com a história de abertura democrática e com o movimento de universalização da Educação Básica, momento no qual se constrói, especialmente nas décadas de 1980 e 1990, a perspectiva de uma "matemática para todos". Como a presença da Matemática na cultura escolar brasileira é fortemente identificada por processos de seleção, de exclusão e de classificação, recai sobre nós o compromisso político de revisitar a história social e cultural da Matemática escolar buscando, no presente, reconfigurá-la em termos de ideais democráticos.

Recentemente, assistimos aos ideais democráticos que defendemos sendo ameaçados por reformas educacionais autoritárias, como a Reforma do Ensino Médio ou a proposição de uma Base Nacional Comum Curricular. Na efervescência dessas discussões, lemos um Manifesto da Sociedade Brasileira de Matemática (SBM) que, na contramão de suas Sociedades científicas coirmãs ${ }^{5}$, tenta reforçar e legitimar a história de seleção, de exclusão e de

\footnotetext{
${ }^{5}$ A título de exemplo, podemos citar a Nota Pública da Sociedade Brasileira de Progresso da Ciência (SBPC), publicada em 22 de março de 2017, que manifesta "preocupação quanto às consequências curriculares da Lei 13.415, de 16/02/17, que institui mudanças na oferta e organização do Ensino Médio no país" (SBPC, 2017).
} 
classificação que põe o ensino de Matemática à serviço do mercado e que considera o nosso Ensino Médio - para usar as palavras do documento - "ineficiente", "desestimulante" e "um desperdício de recursos". Vimos a SBM afirmar que o nosso Ensino Médio é "carregado com número excessivo de disciplinas obrigatórias com programas extensos", que "sequer garante um aprendizado minimamente adequado nas áreas mais fundamentais: Língua Portuguesa e Matemática" (SBM, 2016).

O sentimento de contraposição a esse manifesto da SBM nos faz lembrar de um texto de Ubiratan D'Ambrosio, publicado nos Anais do I SIPEM, intitulado Desafios da Educação Matemática no ano 2000. Nele, D’Ambrosio (2000, p. 18) afirma que "a matemática e a educação matemática não podem ser insensíveis aos problemas maiores afetando o mundo moderno, principalmente a exclusão de indivíduos, comunidades, e até nações, dos benefícios da modernidade". Por isso, e a partir da fala do professor Ubiratan, acreditamos ser inegável a necessidade e a urgência de discutirmos formas e conteúdos que nos permitam enfrentar as dificuldades históricas e estruturais de nossa Educação Básica; mas é igualmente inegável que, se julgamos a democracia um benefício da modernidade, devemos orientar essas discussões e ações não no sentido da educação como serviço, mas na direção dos ideais democráticos que afirmam o bem comum, o interesse coletivo e o respeito, a valorização e a promoção da diversidade.

Nesses 30 anos, nossa responsabilidade política procurou aliar os processos educativos e formativos ligados à Matemática de modo que aos sujeitos da educação fossem garantidos seus direitos civis, sociais e políticos mais fundamentais. Recentemente, reafirmamos essa responsabilidade em uma Nota que, vigorada pela noção de justiça social que tem orientado o trabalho dos educadores matemáticos brasileiros, externa sua "preocupação com a alarmante escalada de ameaças à democracia, concretizadas pela apologia ao obscurantismo cultural e científico, à violência, à tortura e a todas as formas de intolerância". Colocamo-nos de modo veementemente contrário, como expresso no documento, a

\begin{abstract}
qualquer proposta ou plataforma política que firam os princípios fundantes da democracia, do respeito e da incorporação da diversidade de raça, credo, gênero, orientação sexual, identidade de gênero; que cerceiem a liberdade de atuação profissional de professoras e professores, respeitados os princípios básicos da ética da profissão; a imposição de currículos baseados em pautas autoritárias, sem compromissos com a produção científica e cultural da humanidade; a escola como espaço de reflexão crítica e de produção de saberes (SBEM, 2018).
\end{abstract}

Neste momento em que convivemos com discursos de sugerem o cerceamento de nossas liberdades individuais e profissionais, devemos insistentemente reafirmar nosso compromisso com a avaliação do reconhecimento social da Matemática e suas contribuições para a formação 
política dos estudantes e futuros professores da Educação Básica, fomentando a coragem para interpelar os desafios de nosso tempo, na intenção de superá-los. Devemos usar o reconhecimento social da Matemática e do professor de Matemática não como meio de favorecimento, mas, como diz Antonio Miguel, uma "possibilidade para se pensar que reivindicando, praticando e tomando partido por um outro tipo de escolarização, neste nosso mundo, é possível antecipar outros mundos possíveis" (MIGUEL, 2016, p. 363).

Além dessas duas responsabilidades - a epistemológica e a política, indissociáveis - e de nosso radical compromisso com a democracia, podemos delinear uma terceira e última responsabilidade, provavelmente a mais ligada à pergunta “quem somos nós?". Essa responsabilidade, que desenvolvo em termos de responsabilidade pela subjetividade, busca entender como o pertencimento à SBEM e ao lastro histórico de sua constituição e atuação permite a elaboração do que somos, de quem somos, do que nos tornamos, de como nos tornamos o que somos, do que não podemos e não queremos ser ou do que já deixamos de ser.

Particularmente no Seminário Internacional de Pesquisa em Educação Matemática, fórum privilegiado da comunidade científica que participa de nossa Sociedade e que se dedica à pesquisa acadêmica em Educação Matemática, desenhar essa responsabilidade é conviver e sustentar uma inquietação: em que medida nossas pesquisas se preocupam e se comprometem com as demandas de nosso tempo? A SBEM surge em tempos de afirmação da democracia e, como que em um avesso, comemora seus 30 anos em um momento de instabilidade democrática. De um tempo que poderia ficar no passado, devemos revisitar as narrativas que constituem a memória coletiva de nossa Sociedade somando esforços para, mais uma vez, direcionarmos nossas ações como comunidade - nossa autoridade de falar, nossa autoridade de orientar, nossa autoridade de produzir, nossa autoridade de pesquisar - para o enfrentamento dos desafios colocados por nosso tempo.

Nesse sentido, a responsabilidade pela subjetividade exige uma atenção a nossas próprias histórias, de modo que nossas experiências individuais e coletivas ajudem a pensar a SBEM de novo e de uma nova maneira, (re)movendo os sentidos que construímos, as lutas que reivindicamos, as ações que encorajamos, as posições que assumimos e negamos, os caminhos que percorremos e os que podemos percorrer, o que nos convida a existir e a continuar existindo como Sociedade.

Buscando articular as discussões presentes neste texto, trazemos, como imagem final das intenções aqui delineadas, um relato pessoal da professora e historiadora María Milagros Rivera Garretas, da Universidade de Barcelona, que traz uma dimensão viva e assumidamente 
feminina para a produção da história, uma motivação para a tarefa de avaliação de nossa memória coletiva em face ao enfrentamento dos tempos que se aproximam. Diz a historiadora:

\begin{abstract}
Durante muitos anos ministrei em minha Faculdade a disciplina Tendências historiográficas atuais. Ao chegar à historiografia sobre o Holocausto, a participação dos alunos era intensíssima. Liam e comentavam todo tipo de obra, faziam registros audiovisuais, resgatavam o testemunho de sobreviventes... Mas, ao final, eu não ficava satisfeita: todo aquele interesse me angustiava. Não ficava satisfeita porque ficava sempre, entre os bastidores, o ódio ao povo alemão pelo delito cometido. Quer dizer: não havia resgate, não havia redenção, nem culpa e nem memória, porque não há a redenção se o ódio prevalece. E, se não há redenção, a história pode repetir-se. Não havia resgate nem redenção da memória porque eu não soube encontrar a porta estreita que deixaria passar o amor na interpretação da história (GARRETAS, 2007, p. 35-36, tradução nossa).
\end{abstract}

\title{
Referências
}

BLOCH, Marc. Apologia da história ou o ofício de historiador. Rio de Janeiro: Jorge Zahar Ed., 2001.

CASTRO, A. D. A licenciatura no Brasil. Revista de História. São Paulo, v. 50, n. 100, p. 627-652, out./dez., 1974.

D’AMBROSIO, U. Desafios da educação matemática nos anos 2000. In: SIMPÓSIO

INTERNACIONAL DE PESQUISA EM EDUCAÇÃO MATEMÁTICA, 1, 2000, Serra Negra (SP).

Anais... Brasília: SBEM, 2000.

DIAS, A. L. M. Da bossa das matemáticas à educação matemática: disputas por uma jurisdição profissional. 2002. Disponível em:

<http://www.academia.edu/4184238/DA_BOSSA_DAS_MATEM\%C3\%81TICAS_\%C3\%80_EDUC A\%C3\%87\%C3\%830_MATEM\%C3\%81TICA_DISPUTAS_POR_UMA_JURISDI\%C3\%87\%C3\% 83O_PROFISSIONAL>. Acesso em: 15 out. 2018.

FERNANDES, F. S.; ARAÚJO, P. H. S.; COSENZA, L. H. C. A. Didática Especial e História da Educação Matemática: contribuições de um estudo sobre a formação de professores de matemática na Faculdade de Filosofia de Minas Gerais (Belo Horizonte, p. 1941-1954). 2019. (no prelo)

GARRETAS, M. M. R. La historia que resgata y redime el presente. Duoda: estudis de la diferència sexual, n. 33, p. 27-39. 2007.

GOMES, M. L. M. Os 80 anos do primeiro curso de Matemática brasileiro: sentidos possíveis de uma comemoração acerca da formação de professores no Brasil. Bolema, v. 30, n. 55, p. 424-438, ago. 2016.

HOFSTETTER, R.; SCHNEUWLY, B. Disciplinarização e disciplinação: as ciências da educação e as didáticas das disciplinas sob análise. In: HOFSTETTER, R.; VALENTE, W. R. (Org.). Saberes em (trans)formação: tema central da formação de professores. São Paulo: Editora Livraria da Física, 2017.

MIGUEL, A. Entre jogos de luzes e sombras: uma agenda contemporânea para a educação matemática brasileira. Perspectivas da Educação Matemática, v. 9, n. 20, p. 323-365, 2016.

MONTESSORI, M. Psychogéometrie - L'étude de la géométrie fondée sur la psychologie de l'enfant. Rennes, France: CRELAM/Desclée de Brouwer, 1934 [2007]. 
PEREIRA, D. J. R. História do movimento democrático que criou a Sociedade Brasileira de

Educação Matemática - SBEM. 2005. 261 f. Tese (Doutorado em Educação) - Faculdade de Educação, Universidade Estadual de Campinas, Campinas, 2005.

SOCIEDADE BRASILEIRA DE MATEMÁTICA - SBM. Conselho Diretor. Manifesto da Sociedade Brasileira de Matemática sobre a Reforma do Ensino Médio. 2016. Disponível em: <https://www.sbm.org.br/noticias/manifesto-da-sociedade-brasileira-de-matematica-sobre-a-reformado-ensino-medio>. Acesso em: 8 out. 2018.

SOCIEDADE BRASILEIRA DE EDUCAÇÃO MATEMÁTICA - SBEM. Nota Pública. 2018. Disponível em: <http://www.sbembrasil.org.br/sbembrasil/index.php/noticias/837-nota-publica>. Acesso em: 8 out. 2018.

SOCIEDADE BRASILEIRA PARA O PROGRESSO DA CIÊNCIA - SBPC. Nota Pública. 2017. Disponível em: <https://drive.google.com/file/d/0B-h7ieF7jdYXT3hzOWITdTFxWUU/view>. Acesso em: 8 jan. 2019.

VALENTE, W. R. Uma história da matemática escolar no Brasil, 1730-1930. São Paulo: Annablume/FAPESP, 2a. ed., 2007. 